Article

\title{
Production and Characterization of Glass-Ceramic Materials for Potential Use in Dental Applications: Thermal and Mechanical Properties, Microstructure, and In Vitro Bioactivity
}

\author{
Francesco Baino * (iD) and Enrica Verné \\ Institute of Materials Physics and Engineering, Department of Applied Science and Technology, \\ Politecnico di Torino, Corso Duca degli Abruzzi 24, 10129 Torino, Italy; enrica.verne@polito.it \\ * Correspondence: francesco.baino@polito.it; Tel.: +39-011-090-4668
}

Received: 19 November 2017; Accepted: 18 December 2017; Published: 20 December 2017

\begin{abstract}
Multicomponent silicate glasses and their corresponding glass-ceramic derivatives were prepared and tested for potential applications in dentistry. The glasses were produced via a melting-quenching process, ground and sieved to obtain fine-grained powders that were pressed in the form of small cylinders and thermally treated to obtain sintered glass-ceramic samples. X-ray diffraction investigations were carried out on the materials before and after sintering to detect the presence of crystalline phases. Thermal analyses, mechanical characterizations (assessment of bending strength, Young's modulus, Vickers hardness, fracture toughness), and in vitro bioactivity tests in simulated body fluid were performed. On the basis of the acquired results, different potential applications in the dental field were discussed for the proposed glass-ceramics. The use of such materials can be suggested for either restorative dentistry or dental implantology, mainly depending on their peculiar bioactive and mechanical properties. At the end of the work, the feasibility of a novel full-ceramic bilayered implant was explored and discussed. This implant, comprising a highly bioactive layer expected to promote osteointegration and another one mimicking the features of tooth enamel, can have an interesting potential for whole tooth substitution.
\end{abstract}

Keywords: bioactive glasses; glass-ceramics; restorative dentistry; dental implant

\section{Introduction}

Materials for dental applications can be essentially divided into two main groups: materials for restorative dentistry and materials for dental implantology [1,2]. These two types of materials differ in their application environment, preferred properties, and end use. The main requirement that the materials belonging to the first class should fulfil is the compatibility with the oral environment, as dental restorations pursue the aim to substitute the natural tooth enamel. The tooth is mainly constituted of two elements: (i) the outer enamel (2-3 mm in thickness at the tip of each tooth), subjected to the chemical environment within the mouth and to the loads due to chewing and biting; and (ii) the dentine, which lies underneath the enamel [3]. If the enamel is breached due to tooth fracture, cracking, or wear, the dentine is directly exposed to the mouth environment [4]. The key attributes of enamel are the excellent wear resistance and the ability to support a wide range of loads due to mastication. In addition, the outer surface of tooth undergoes severe working conditions, e.g., reciprocating movements, impacts, thermal shocks, and acid attacks [5]. Therefore, tooth enamel is characterized by unique tribological properties that can only partly be reproduced by artificial restorative materials.

Bioceramics are very promising materials for dental restoration due to their chemical stability, proper aesthetics, and durability. Organic/inorganic composites, made of glass, glass-ceramic, 
or ceramic particles embedded in a polymeric matrix, have been widely used in dentistry for three decades [6-8]. In addition, bioceramics have also been used alone as fillers for small cavities occurring on tooth enamel. Specifically, glass-ceramics with controlled chemical, mechanical, and aesthetic properties have been proposed as materials for dental restoration. The first compositions, developed in the early 1970s, belonged to the $\mathrm{Li}_{2} \mathrm{O}-\mathrm{ZnO}-\mathrm{SiO}_{2}$ system; other systems based on leucite or mica phases have been more recently investigated [9-11].

The situation is different as regards the materials used for implantological applications, as they have to exhibit bioactive properties, i.e., the ability to (i) bond to the alveolar bone; (ii) promote the growth of new bone tissue; and (iii) create a stable interface between the implant and the host bone [12]. Optical or aesthetic properties, such as a good degree of whiteness, are not fundamental for these applications. Depending on the particular clinical case, the implant may be load-bearing or not and, therefore, it may be expected to fulfil some specific mechanical requirements in terms of bending stress, toughness, and Young's modulus. The toughness of bioceramics is usually much lower than that of tooth structures: this is the major reason why metals are often used to replace the root of the tooth instead of ceramics. Due to their favourable mechanical strength, biocompatibility, and light weight, pure titanium and its alloys (e.g., the well-known Ti-6Al-4V) have extensively been studied and proposed for dental implantology [13]. In order to promote osteointegration, hydroxyapatite (HA)-coated metal implants have been developed [14]. In fact, HA-coated implants combine the mechanical advantages of metal alloys with the bioactivity of HA due to its chemical and crystallographic similarity to the carbonated bio-apatite in human teeth and bone [15].

Ceramic or polymer/ceramic composite restorative crowns can be mounted on dental implants that aim to treat edentulism (toothlessness) by serving as anchors for partial, single-tooth, or full-arch dental prostheses [16-18]. Other advanced applications of bioceramics and bioactive glasses in modern dentistry, including their use for sealing the root canal, regenerating the alveolar bone, and treating dentinal hypersensitivity, have been comprehensively reviewed by other authors [19-24].

In the present work, non-commercial multicomponent silicate glasses, which were initially designed for bone tissue engineering applications [25], and their glass-ceramic derivatives were produced and investigated by thermal analysis, $\mathrm{X}$-ray diffraction, mechanical characterizations, and in vitro bioactivity tests. The choice of these materials was dictated by the fact that glasses and glass-ceramics offer a unique and wide versatility, in terms of composition-processing-properties relationships, compared to other dental materials. Depending on the different features of the materials, different applications and end uses were suggested for both restorative applications and dental implantology. An early bilayered prototype implant, coupling two of the investigated glass-ceramics, was also tailored and proposed for the replacement of the whole tooth.

\section{Materials and Methods}

\subsection{Synthesis of the Starting Materials}

The molar compositions of the three glasses used as starting materials in this work are listed in Table 1. As regards glass preparation, the reagents (high-purity oxides, carbonates, or appropriate salts all purchased from Sigma-Aldrich, St. Louis, MO, USA) were homogenously mixed in a platinum crucible and heated in air at a rate of $10{ }^{\circ} \mathrm{C} \cdot \mathrm{min}^{-1}$ in an electrical furnace (Table 1). After being held for $1 \mathrm{~h}$ at the melting temperature to ensure the homogeneity of the melt, the glass was quenched in cold water to obtain a "frit" that was ground by ball milling (Pulverisette 0 equipped with a $\mathrm{ZrO}_{2}$ ball, Fritsch, Idar-Oberstein, Germany) and sieved (stainless steel sieves, Giuliani Technology) to a final grain size below $32 \mu \mathrm{m}$. 
Table 1. Compositions and preparation details of the starting materials.

\begin{tabular}{cccccccccc}
\hline \multirow{2}{*}{ Glass Name } & \multicolumn{8}{c}{ Composition (mol.\%) } & \multirow{2}{*}{ Melting Conditions } \\
\cline { 2 - 7 } & $\mathrm{SiO}_{\mathbf{2}}$ & $\mathbf{P}_{\mathbf{2}} \mathbf{O}_{\mathbf{5}}$ & $\mathbf{C a O}$ & $\mathbf{N a}_{\mathbf{2}} \mathbf{O}$ & $\mathbf{M g O}$ & $\mathbf{K}_{\mathbf{2}} \mathbf{O}$ & $\mathbf{A l}_{\mathbf{2}} \mathbf{O}_{\mathbf{3}}$ & $\mathbf{C a F}_{\mathbf{2}}$ & \\
\hline CEL2 & 45 & 3 & 26 & 15 & 7 & 4 & - & - & $1400^{\circ} \mathrm{C}$ for $1 \mathrm{~h}$ \\
FaGC & 50 & 6 & 18 & 7 & 3 & 7 & - & 9 & $1550^{\circ} \mathrm{C}$ for $1 \mathrm{~h}$ \\
SCNA & 57 & - & 34 & 6 & - & - & 3 & - & $15500^{\circ} \mathrm{C}$ for $1 \mathrm{~h}$ \\
\hline
\end{tabular}

\subsection{Characterization of the Starting Materials}

\subsubsection{Thermal Analysis}

The characteristic temperatures of the materials, i.e., glass transition temperature $\left(\mathrm{T}_{\mathrm{g}}\right)$, crystallization temperature $\left(T_{x}\right)$, and melting temperature $\left(T_{m}\right)$, were assessed by differential thermal analysis (DTA; DTA-7, Perkin Elmer) carried out on powdered glass samples in the range $50-1400{ }^{\circ} \mathrm{C}$ with a heating rate of $20^{\circ} \mathrm{C} \cdot \mathrm{min}^{-1} ; \mathrm{Al}_{2} \mathrm{O}_{3}$ powder was used as a reference.

The thermal expansion coefficient $(\alpha)$ was determined by dynamic mechanical analysis (DMA; DMA7 PerkinElmer Inc., Waltham, MA, USA).

\subsubsection{X-ray Diffraction Analysis}

The as-poured materials, after being ground in powders, were investigated from a structural viewpoint through wide-angle ( $2 \theta$ within $\left.10-70^{\circ}\right)$ X-ray diffraction analysis (XRD); a X' Pert Philips diffractometer (PANalytical, Eindhoven, The Netherlands; $\mathrm{Cu}$ anode, $\mathrm{K} \alpha$ radiation with wavelength $\lambda=15.405 \mathrm{~nm}, \Delta(2 \theta)=0.02^{\circ}$, fixed counting time of $1 \mathrm{~s}$ per step) operating at $40 \mathrm{kV}$ and $30 \mathrm{~mA}$ was used. Crystalline phases were identified by making use of $X^{\prime}$ Pert HighScore software (2.2b) equipped with the PCPDFWIN database (http:/ / pcpdfwin.updatestar.com/).

\subsection{Preparation of the Glass-Ceramic Samples}

CEL2, FaGC, and SCNA powders were uniaxially (1-D) pressed in the form of cylinders (diameter $10 \mathrm{~mm}$, height $10 \mathrm{~mm}$ ); the pressing conditions were set at $500 \mathrm{MPa}$ for $60 \mathrm{~s}$ to obtain crack-free "green" bodies. Samples for flexural testing $(52 \mathrm{~mm} \times 10 \mathrm{~mm} \times 4 \mathrm{~mm})$ were also produced by a similar approach. Ethanol (Sigma-Aldrich, St. Louis, MO, USA) was used as a binder for the glass particles. After being compacted, the so-obtained "greens" were thermally treated (TT) in air to produce sintered glass-ceramic samples, hereafter referred to as TT-CEL2, TT-FaGC, and TT-SCNA. The specimens were heated at a rate of $5^{\circ} \mathrm{C} \cdot \mathrm{min}^{-1}$ up to the proper sintering temperature, reported in Table 2; after being held at the desired temperature for $3 \mathrm{~h}$, they were left to cool inside the furnace to room temperature at a rate of $10{ }^{\circ} \mathrm{C} \cdot \mathrm{min}^{-1}$. The sintering parameters were chosen on the basis of preliminary hot-stage microscopy results (reported elsewhere [26-28]) and DTA in order to achieve a good densification along with the minimum shrinkage of the final glass-ceramic samples.

Table 2. Sintered glass-ceramic samples: preparation details and resulting densities.

\begin{tabular}{cccc}
\hline Sample & Parent Material & Sintering Conditions & $\rho_{\mathbf{s}}\left(\mathbf{g} \cdot \mathbf{c m}{ }^{-3}\right)$ \\
\hline TT-CEL2 & CEL2 & $1000{ }^{\circ} \mathrm{C}$ for $3 \mathrm{~h}$ & $2.46 \pm 0.10$ \\
TT-FaGC & FaGC & $800{ }^{\circ} \mathrm{C}$ for $3 \mathrm{~h}$ & $2.50 \pm 0.12$ \\
TT-SCNA & SCNA & $1000^{\circ} \mathrm{C}$ for $3 \mathrm{~h}$ & $2.53 \pm 0.11$ \\
\hline
\end{tabular}




\subsection{Characterization of the Glass-Ceramic Samples}

\subsubsection{X-ray Diffraction Analysis}

The sintered glass-ceramics were ground into powders and investigated by wide-angle XRD, as described in the Section 2.2.2, in order to detect the presence of crystalline phases developed during the thermal treatment.

\subsubsection{Physical and Mechanical Characterizations}

The density of the sintered glass-ceramic cylinders was assessed by geometrical mass-volume measurements; the resulting values are presented in Table 2 . The total porosity $P$ (vol.\%) was calculated as:

$$
P=\left(1-\frac{\rho_{s}}{\rho_{0}}\right) \times 100
$$

where $\rho_{s}$ is the apparent density of the glass-ceramic sample (mass-to-volume ratio) and $\rho_{0}$ is the theoretical density of non-porous material.

Three-point flexural tests were carried out for glass-ceramic samples with a rectangular section (sample dimensions: $52 \mathrm{~mm} \times 10 \mathrm{~mm} \times 4 \mathrm{~mm}$ ); the bending stress $\sigma_{b}(\mathrm{MPa})$ was calculated as [29]:

$$
\sigma_{b}=\frac{3 F_{b} L}{2 b^{2} h}
$$

where $F_{b}$ is the applied load, $L$ is the distance between the supports, and $b$ and $h$ are the sizes of the sample section.

Prior to undergoing microhardness measurements, the surface of the samples was polished by $\mathrm{SiC}$ grit papers (\#4000 max.). The Vickers hardness (HV) of the glass-ceramics was measured by using a microhardness tester (Leica Microsystem, Milan, Italy); indentations were performed at $5 \mathrm{~N}$ for $20 \mathrm{~s}$ and the value of $H V(\mathrm{GPa})$ was calculated as:

$$
H V=\frac{2 F_{H} \sin (\beta / 2)}{d^{2}}
$$

where $F_{H}$ is the load applied during the test, $\beta=136^{\circ}$ is the angle of the indenting tip, and $d(\mu \mathrm{m})$ is the length of the diagonal of the imprint.

The fracture toughness $K_{\mathrm{IC}}\left(\mathrm{MPa} \cdot \mathrm{m}^{1 / 2}\right)$ was estimated according to Anstis et al. [30] as:

$$
K_{I C}=0.016 F_{H} \frac{(E / H V)^{1 / 2}}{c^{3 / 2}}
$$

where $E$ is the Young's modulus and $c$ is the average length of the cracks created by the imprint.

The elastic modulus $E$ in Equation(4) was experimentally assessed in a non-destructive way by using the impulse excitation technique, which is based on the analysis of the specimen's transient natural vibration resulting from mechanical impact (Lemmens Grindosonic instrument, Leuven, Belgium) [31]. This approach was also followed by other authors for investigating dental materials [32].

Density, porosity, and all the results of mechanical tests were expressed as mean \pm standard deviation calculated for five samples.

\subsubsection{In Vitro Bioactivity}

In vitro bioactivity tests were carried out on TT-CEL2, TT-FaGC, and TT-SCNA small disks (diameter $10 \mathrm{~mm}$, height $5 \mathrm{~mm}$ ) by soaking the samples for seven days in $30 \mathrm{~mL}$ of simulated body fluid (SBF) prepared according to the Kokubo's protocol [33]. The specimens were maintained at $37^{\circ} \mathrm{C}$ in sealed polyethylene bottles and the solution was refreshed twice a week. After being extracted from the flask at the end of the test, the samples were gently rinsed with distilled water and left to dry 
overnight at ambient temperature. Then, they were sputter-coated with an ultrathin layer of silver and investigated by scanning electron microscopy (SEM; QUANTA INSPECT 200, FEI, Eindhoven, The Netherlands; accelerating voltage $15 \mathrm{kV}$ ), energy dispersive spectroscopy (EDSPV 9900, EDAX, Mahwah, NJ, USA) for compositional analysis, and wide-angle XRD.

\subsection{Proposal of Application: Design and Development of a Bilayered Glass-Ceramic Implant}

The feasibility of a novel glass-derived bilayered implant, formed by two different materials, was explored. The idea was to develop an implant comprising a bioactive "bottom layer", which can promote osteointegration with the alveolar bone, and an aesthetic "top layer". On the basis of the analyses carried out on the previously prepared materials, CEL2 and SCNA were selected to fabricate a prototype of this new implant that was obtained by stacking and then uniaxially pressing (500 MPa for $60 \mathrm{~s}$ ) the two layers of glass powders. The process of fabrication is schematically depicted in Figure 1. The so-obtained "green" body was thermally treated at $1000{ }^{\circ} \mathrm{C}$ for $3 \mathrm{~h}$ to allow the sintering of the glass particles, and cylindrical implants (diameter $\sim 10 \mathrm{~mm}$, height $\sim 20 \mathrm{~mm}$ ) were finally obtained.

(a)

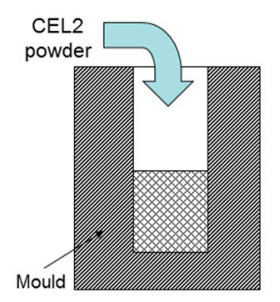

(b)

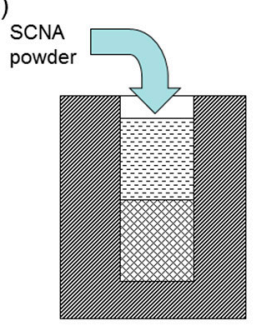

(c)

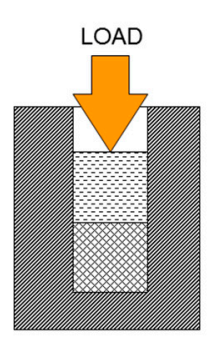

(d)

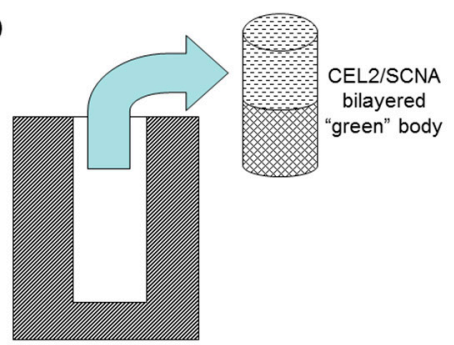

Figure 1. Preparation of the bilayered glass-derived samples for potential use in dental implantology: casting of (a) CEL2 powders; and (b) SCNA powders in the mould; (c) 1-D pressing; and (d) extraction from the mould.

The joining region between the two layers was carefully investigated by SEM analysis in order to detect the presence of interfacial cracks or discontinuities. For this purpose, the samples were embedded in epoxy resin (Struers Epofix, Willich, Germany), cut by a diamond saw (Struers Accutom 5, Willich, Germany), and carefully polished by $\mathrm{SiC}$ grit papers (\#4000 max.).

In vitro tests were carried out on this bilayered implant by soaking the sample for seven days and one month in SBF, in order to enhance the different behaviour of the two layers when put into contact with biological fluids. After being extracted from the flask at the end of the test, the sample was gently rinsed with distilled water and left to dry overnight at ambient temperature. Then, it was cut by a diamond saw, polished by SiC grit paper, sputter-coated with silver, and analysed by SEM to detect the modifications that had occurred on its surface.

\section{Results}

\subsection{Starting Materials}

\subsubsection{Thermal Analysis}

DTA results $\left(T_{g}, T_{x}, T_{m}\right)$, along with the thermal expansion coefficients, assessed by DMA, are depicted in Table 3. DTA revealed that CEL2 and FaGC showed two crystallization temperatures, whereas only one $T_{x}$ was detected for SCNA. 
Table 3. Results of the thermal analyses carried out for the starting materials.

\begin{tabular}{ccccc}
\hline Material & $\mathbf{T}_{\mathbf{g}}\left({ }^{\circ} \mathbf{C}\right)$ & $\mathbf{T}_{\mathbf{x}}\left({ }^{\circ} \mathbf{C}\right)$ & $\mathbf{T}_{\mathbf{m}}\left({ }^{\circ} \mathbf{C}\right)$ & $\alpha\left(\times \mathbf{1 0}^{-\mathbf{6}}{ }^{\circ} \mathbf{C}^{-\mathbf{1}}\right)$ \\
\hline CEL2 & $550 \pm 10$ & $650 \pm 10 ; 850 \pm 10$ & 1100 & 12.0 \\
FaGC & $520 \pm 10$ & $730 \pm 10 ; 780 \pm 10$ & 1300 & 12.7 \\
SCNA & $690 \pm 10$ & $850 \pm 10$ & 1200 & 8.7 \\
\hline
\end{tabular}

\subsubsection{XRD Investigations}

As shown in Figure 2, CEL2 and SCNA were amorphous materials (only a broad halo is visible in the corresponding XRD spectra of Figure 2a,c), whereas FaGC was a glass-ceramic containing fluoroapatite (FA, $\mathrm{Ca}_{10}\left(\mathrm{PO}_{4}\right)_{6} \mathrm{~F}_{2}$ ) crystals (Figure $2 \mathrm{~b}$ ). Nucleation of FA crystals in FaGC was due to the presence of $\mathrm{CaF}_{2}$ in the starting composition [34]. From a qualitative viewpoint, these results are consistent with the visual appearance of the materials: CEL2 and SCNA, being glasses, were optically transparent to visible light, whereas FaGC, being a glass-ceramic, was opaque and white.

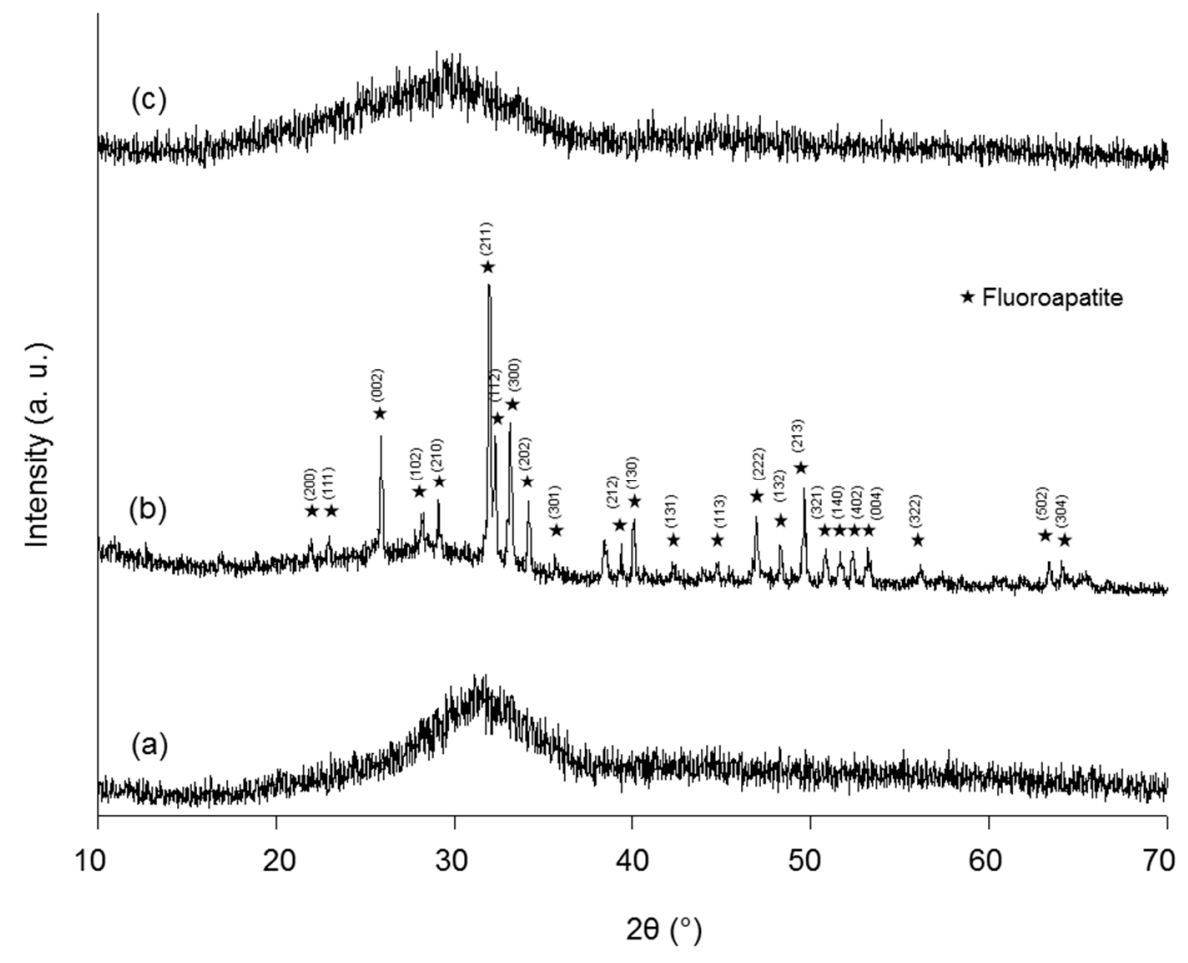

Figure 2. XRD patterns of the as-poured materials: (a) CEL2; (b) FaGC; and (c) SCNA.

\subsection{Glass-Ceramic Derivatives}

\subsubsection{XRD Investigations}

All the three starting materials underwent crystallization upon thermal treatment, thus originating glass-ceramic structures. Specifically, these new phases were identified as follows: $\mathrm{Na}_{2} \mathrm{Ca}_{2}\left(\mathrm{Si}_{3} \mathrm{O}_{9}\right)$ (combeite) and $\mathrm{Ca}_{2} \mathrm{Mg}\left(\mathrm{Si}_{2} \mathrm{O}_{7}\right)$ (akemanite) in TT-CEL2 (Figure 3a); $\mathrm{K}_{3}\left(\mathrm{Na}_{3} \mathrm{Ca}_{5}\right) \mathrm{Si}_{12} \mathrm{O}_{30} \mathrm{~F}_{4} \cdot \mathrm{H}_{2} \mathrm{O}$ (canasite) and FA, which was already found in the as-poured FaGC, in TT-FaGC (Figure 3b); $\mathrm{CaSiO}_{3}$ (wollastonite) in TT-SCNA (Figure 3c). 


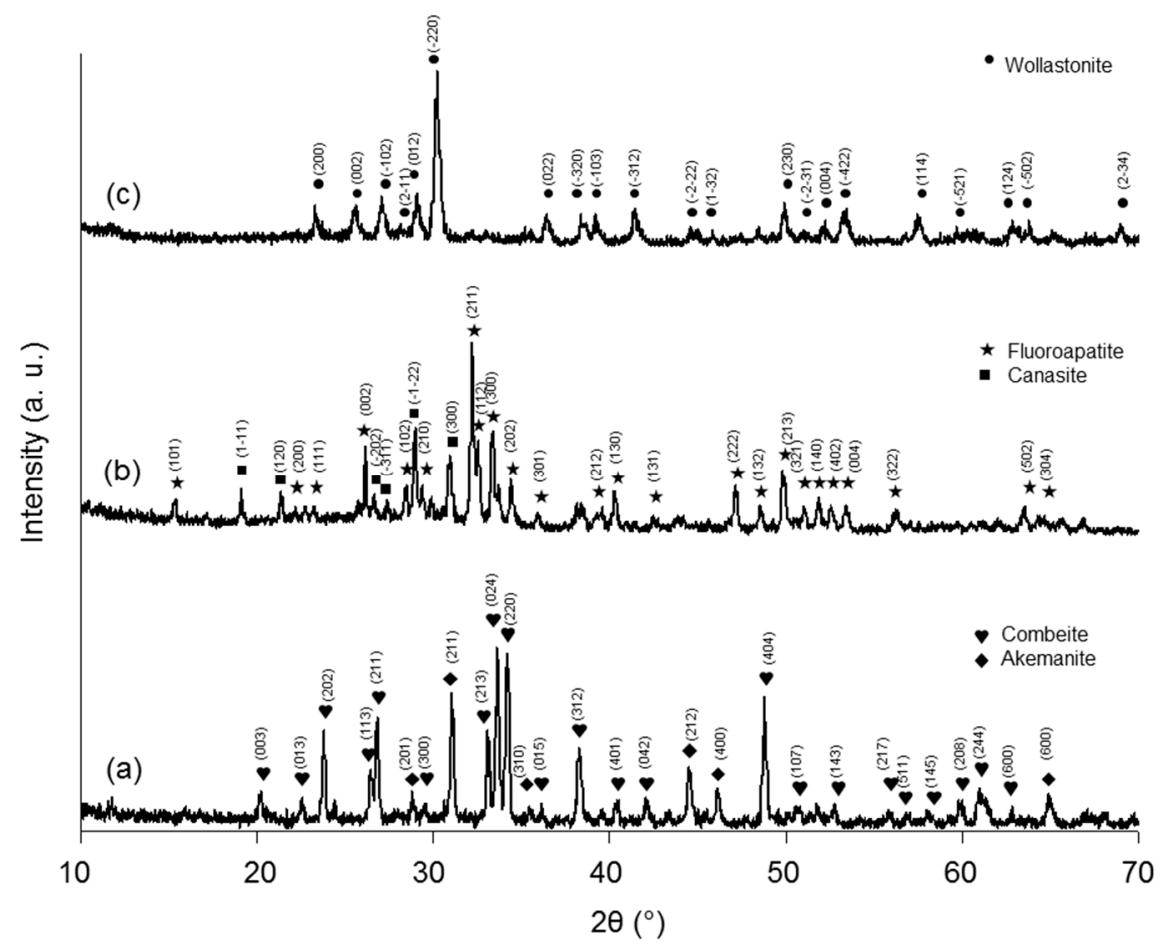

Figure 3. XRD patterns of the sintered materials: (a) TT-CEL2; (b) TT-FaGC; and (c) TT-SCNA.

\subsubsection{Physical and Mechanical Characterizations}

The total porosity of all the sintered glass-ceramic samples ranged within 5-10 vol.\%, thus assessing that a good degree of densification was achieved after sintering. The data resulting from the mechanical characterizations are shown in Table 4. In general, a low standard deviation was determined, which demonstrates the good reproducibility of the specimens.

Table 4. Mechanical properties of the sintered samples.

\begin{tabular}{ccccc}
\hline Sample & $\left.\boldsymbol{\sigma}_{\boldsymbol{b}} \mathbf{( M P a}\right)$ & $\boldsymbol{E}(\mathrm{GPa})$ & $\boldsymbol{H} \boldsymbol{V}(\mathbf{G P a})$ & $\boldsymbol{K}_{\boldsymbol{I C}}\left(\mathbf{M P a} \cdot \mathbf{m}^{\mathbf{1 / 2}}\right)$ \\
\hline TT-CEL2 & $65.0 \pm 21.0$ & $85.0 \pm 2.0$ & $7.4 \pm 0.8$ & $2.40 \pm 0.25$ \\
TT-FaGC & $70.0 \pm 26.0$ & $55.0 \pm 2.0$ & $8.8 \pm 1.3$ & $2.19 \pm 0.20$ \\
TT-SCNA & $125.0 \pm 24.0$ & $98.0 \pm 3.0$ & $11.6 \pm 1.2$ & $2.98 \pm 0.40$ \\
\hline
\end{tabular}

\subsubsection{In Vitro Bioactivity Assessment}

Figure 4 shows the modifications that occurred on the surface of TT-CEL2 after soaking for seven days in SBF. A compact layer of hydroxyapatite (HA), which exhibits a typical "cauliflower" morphology constituted by globular agglomerates, is clearly visible in Figure 4a. Figure $4 \mathrm{~b}$ reveals that the HA agglomerates are made up of nano-sized crystals, which were reported to typically characterize the HA layer formed on the surface of bioactive glasses [35]. The compositional analysis (Figure 4c) showed a Ca-to-P molar ratio of 1.66, which closely approaches the stoichiometric value (1.67) of $\mathrm{HA}$. The presence of silver (Ag) peaks in the EDS pattern is due to the metal coating necessary for the analysis. A weak peak corresponding to silicon ( $\mathrm{Si}$ ) can be attributed to the presence of residual silica gel, which formed during the early stages of the bioactive process as described by Hench and co-workers [36]. 

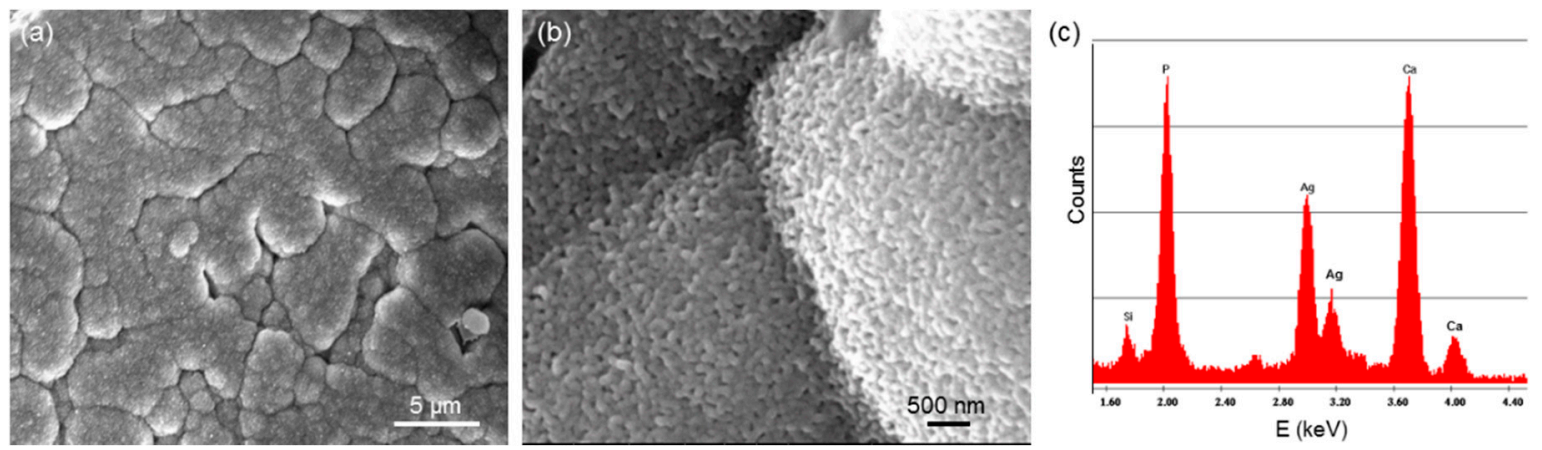

Figure 4. In vitro bioactivity tests carried out on TT-CEL2 samples: $(\mathbf{a}, \mathbf{b})$ sample surface after soaking for seven days in simulated body fluid (SBF) and (c) corresponding energy dispersive spectroscopy (EDS) pattern.

XRD investigations carried out on the sample surface further confirmed the presence of HA, as reported in Figure 5. The major peaks of HA were identified and indexed in the picture, whereas the peaks corresponding to the crystalline phases of TT-CEL2 lying underneath are no longer visible.

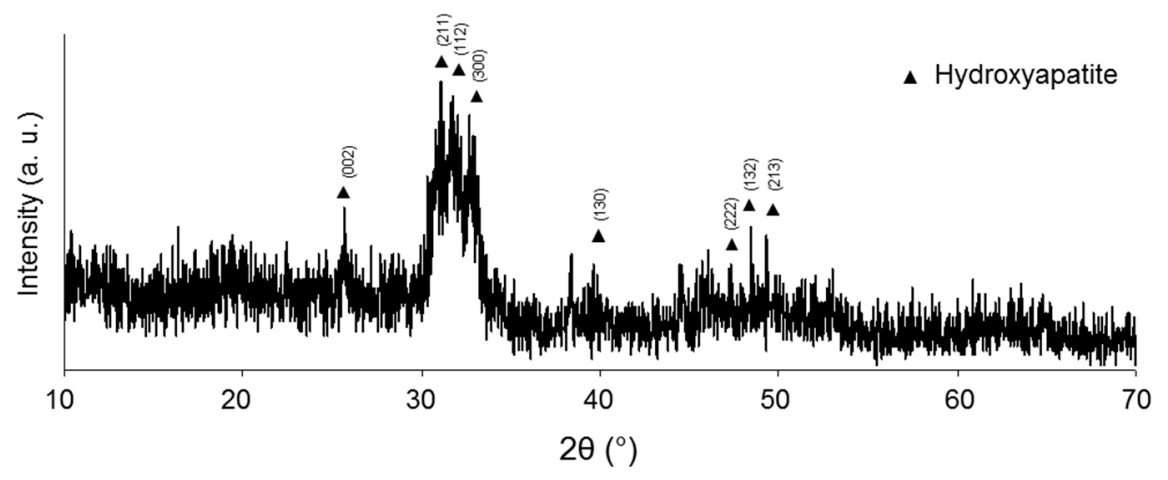

Figure 5. XRD pattern of TT-CEL2 after soaking for seven days in SBF.

Figure 6a shows the surface of TT-FaGC after soaking for seven days in SBF; the corresponding EDS pattern is reported in Figure 6b. The sample surface is still coated by a silica-gel layer: its presence is revealed by the compositional analysis (an intense peak for $\mathrm{Si}$ is visible in Figure $6 \mathrm{~b}$ ) and its typical "clump-like" morphology is due to the condensation of Si-OH groups (stage 3 of the bioactivity mechanism [36,37]). Small globular agglomerates, rich in $\mathrm{Ca}$ and $\mathrm{P}$, are visible on the top of the silica-rich layer: their presence demonstrates that the $\mathrm{CaO}-\mathrm{P}_{2} \mathrm{O}_{5}$-rich film formed on the top of the gel layer begins to crystallize (stages 4 and 5 of the bioactive process [38]). It has to be noticed that the first stage of the bioactive process, i.e., the ion-exchange of cationic species from the glass and $\mathrm{H}^{+}$from the solution, is the rate-determining step for the whole mechanism of bioactivity. On the basis of this consideration, it is possible to give a qualitative explanation of the different bioactive behaviour of TT-CEL2 and TT-FaGC. The amount of residual glassy phase in TT-FaGC is expected to be low, as its parent material (FaGC) was a glass-ceramic and during the thermal treatment, the development of canasite and additional FA occurred (see the Section 3.2.1). Therefore, the limited amount of amorphous phase in TT-FaGC slows down the rate of the bioactive process and, thus, the formation of HA in comparison with TT-CEL2.

TT-SCNA exhibited no apatite-forming ability because of its high content of $\mathrm{SiO}_{2}$ which makes it, as expected, a bioinert material [37]. This behaviour was already studied in a previous work in which null mass loss was detected after prolonged immersion (one month) of thermally-treated SCNA-derived porous implants in SBF [39]. 

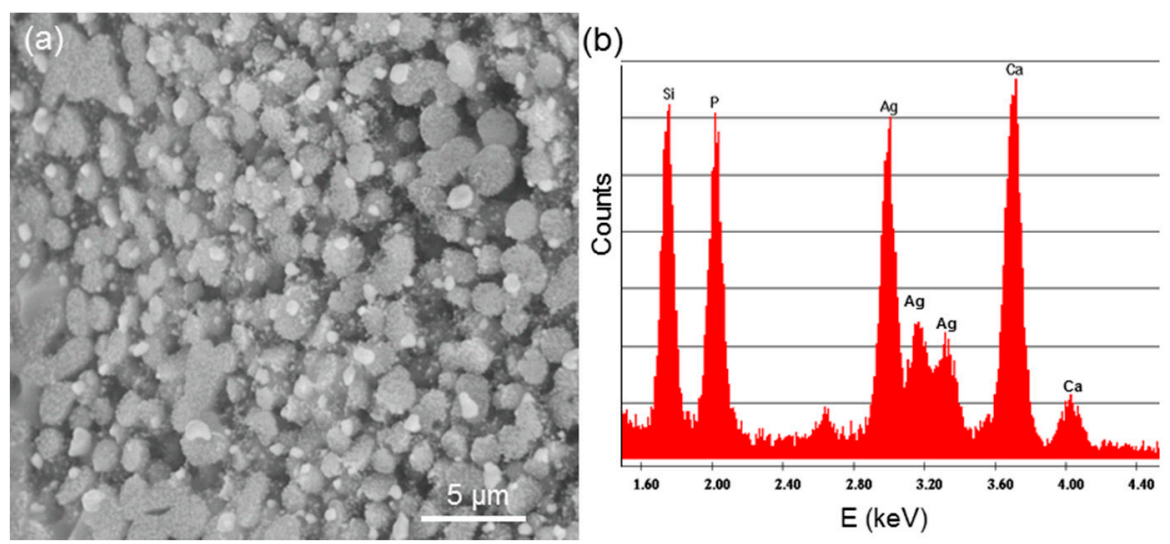

Figure 6. In vitro bioactivity tests carried out on TT-FaGC samples: (a) sample surface after soaking for seven days in SBF and (b) corresponding EDS pattern.

\subsection{Bilayered Glass-Ceramic Implant}

Figure 7 shows the interfacial TT-CEL2/TT-SCNA region of the bilayered glass-ceramic cylindrical implant. This image was acquired by SEM set in back-scattered mode (BSM) to better distinguish the materials of the two layers. In addition, BSM is useful to detect the different phases constituting each layer. As regards TT-SCNA, needle-shaped crystals of wollastonite (white regions) ranging within $10-30 \mu \mathrm{m}$ in length are clearly distinguishable from the amorphous phase (gray regions). On the contrary, the crystalline phases of TT-CEL2 cannot be clearly detected at this magnification due to the small size of the crystals (below $5 \mu \mathrm{m}$ ) and the low contrast between glassy and crystalline phases.

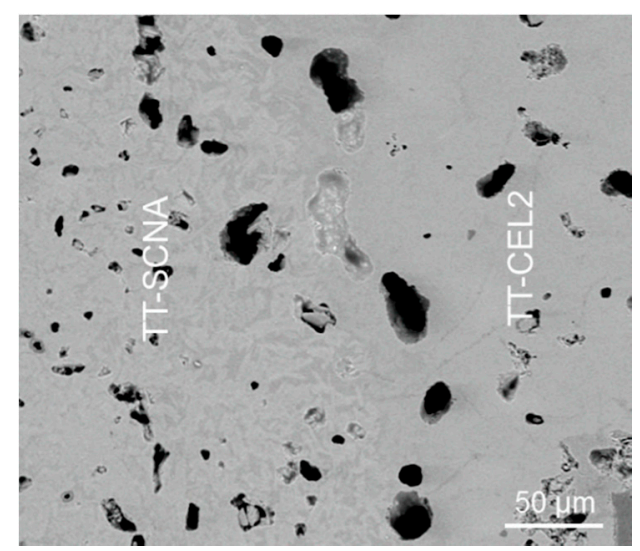

Figure 7. Bilayered glass-ceramic implant: interface between TT-CEL2 and TT-SCNA layers.

As shown in Figure 7, TT-CEL2 and TT-SCNA layers were successfully joined together without any interfacial defects or cracks. Pores ranging within 5-30 $\mu \mathrm{m}$ are visible in both materials: in fact, as mentioned in the Section 3.2.2, a residual porosity is present in the sintered bodies. Future optimization of the glass particle size and pressing conditions will allow a reduction of the pore content of the materials, thus leading to a further improvement of their mechanical properties.

In vitro tests resulted in evidence for the different behaviour of the two regions of the implant put into contact with biological fluids. After immersion for seven days in SBF, no surface modifications occurred on the TT-SCNA layer (Figure 8a), as already mentioned in Section 3.2.3. On the contrary, a continuous and homogeneous layer of HA, with a thickness of $\sim 40 \mu \mathrm{m}$, is clearly visible on the TT-CEL2 surface (Figure 8b). Similar results were observed after immersion for one month in SBF (Figure 9): TT-SCNA continued to exhibit a bioinert behaviour, whereas a HA layer grew in thickness up to $100-150 \mu \mathrm{m}$ on the TT-CEL2 surface. 

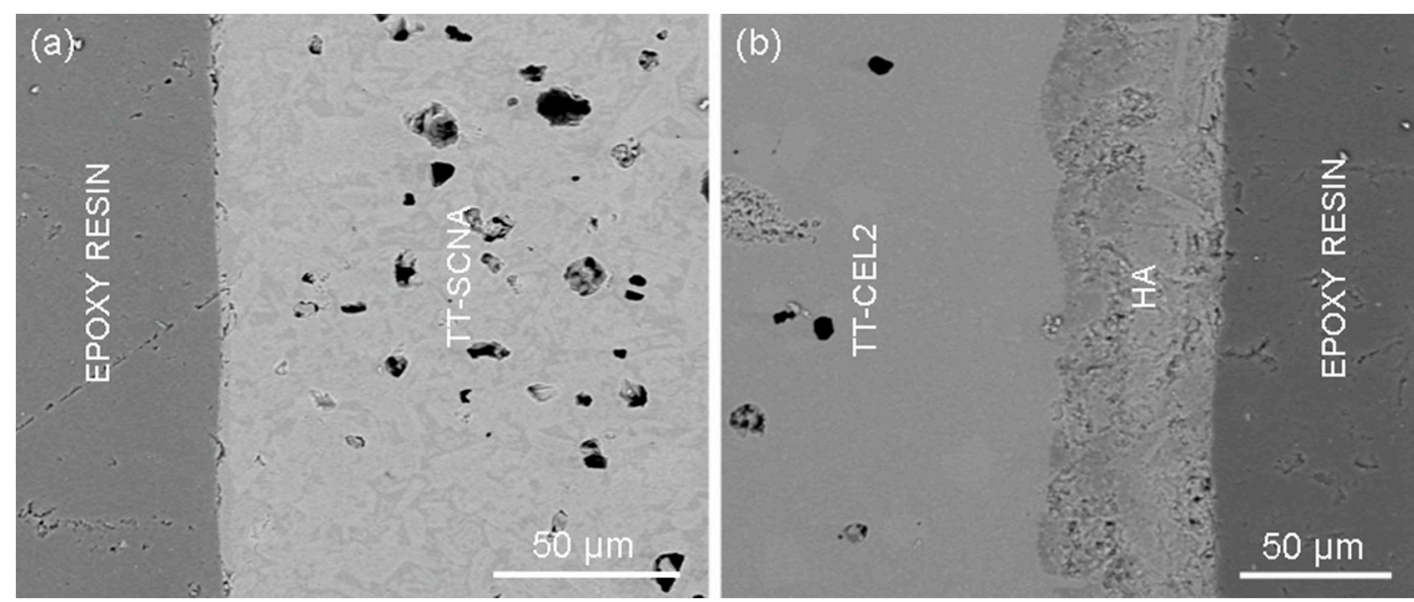

Figure 8. Cross-sections of a bilayered implant after soaking for seven days in SBF: (a) TT-SCNA region and (b) TT-CEL2 region.
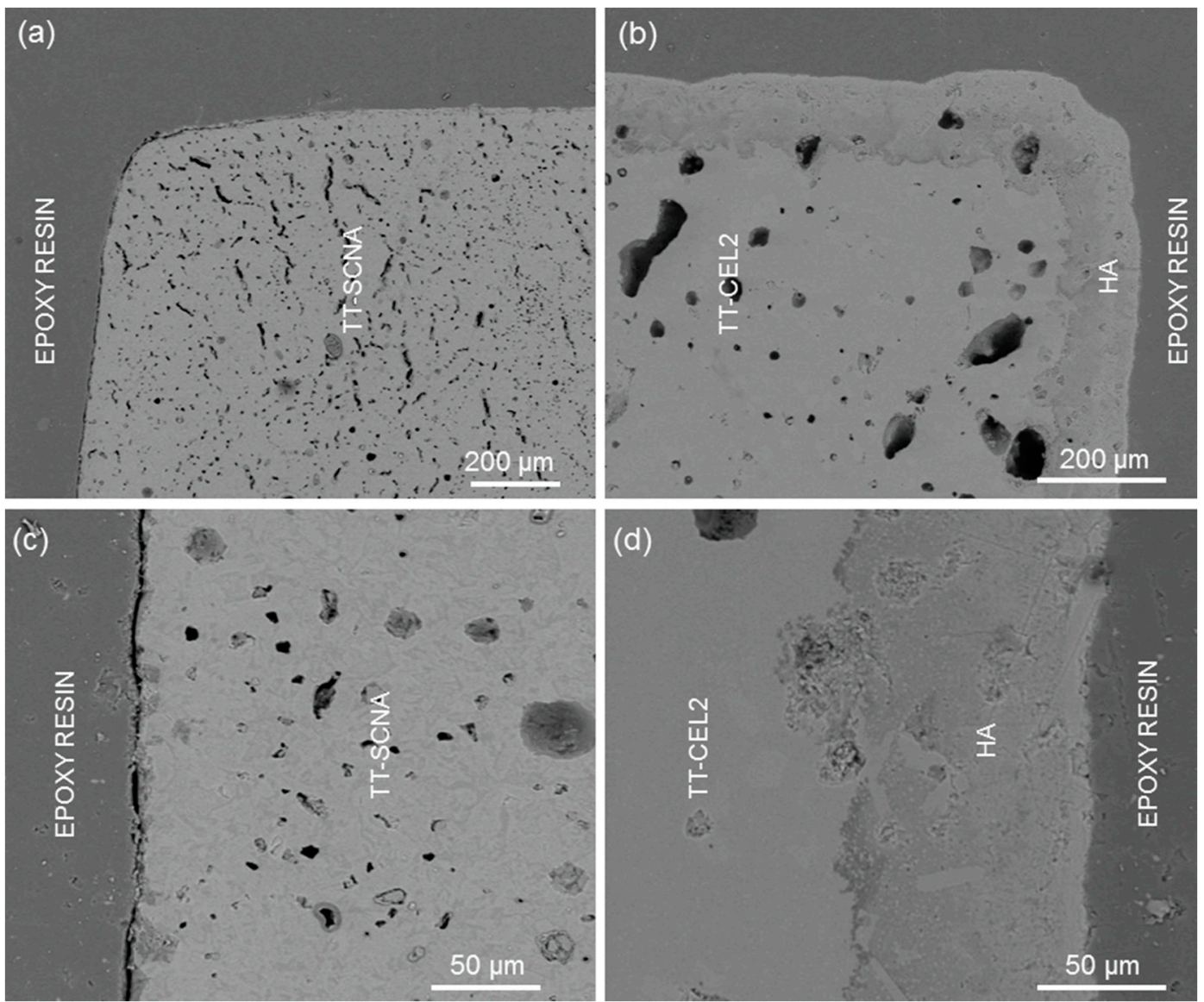

Figure 9. Cross-sections of a bilayered implant after soaking for one month in SBF at different magnifications: $(\mathbf{a}, \mathbf{c})$ TT-SCNA region and $(\mathbf{b}, \mathbf{d})$ TT-CEL2 region.

\section{Discussion}

In this work, three non-commercial multicomponent silicate glasses (CEL2, FaGC, SCNA) were prepared by a melting-quenching process. The corresponding glass-ceramic derivatives (TT-CEL2, TT-FaGC, TT-SCNA) were obtained via thermal treatment of the parent glasses in order to finally produce massive cylindrical or bar-shaped samples. 
Due to the thermal treatment, the development of different crystalline phases occurred in the materials, as shown in Figure 3. As regards TT-CEL2 and TT-SCNA, XRD results are clearly consistent with the data from thermal analysis (Table 3). In fact, the crystalline phases assessed by XRD investigations (Figure $3 a, c$ ) have a direct correspondence with the crystallization temperatures $\left(T_{x}\right)$ found by DTA. With regard to TT-FaGC, the situation is more complex. In fact, it has to be noticed that as-poured FaGC is a glass-ceramic material containing FA crystals. The thermal treatment of sintering induced the development of a new crystalline phase (canasite), as shown in Figure 3b. The DTA analysis showed the presence of two crystallization temperatures, which means that the crystallization of FA, too, continues from the residual glassy phase upon sintering. In general, XRD results are in good agreement with previous findings about thermally-treated CEL2-, FaGC-, and SCNA-derived materials reported elsewhere $[28,40,41]$.

All the three glass-ceramic materials are expected to be highly biocompatible with human tissues, especially bone. As regards the crystalline phases of TT-CEL2, $\mathrm{Na}_{2} \mathrm{Ca}_{2} \mathrm{Si}_{3} \mathrm{O}_{9}$ is the same crystalline phase that develops in $45 \mathrm{~S} 5$ Bioglass ${ }^{\circledR}$ when thermally-treated above $600^{\circ} \mathrm{C}$ [42-44]-This commercial bioactive glass has been implanted since the early 1990s in millions of patients to regenerate bone [45] - And $\mathrm{Ca}_{2} \mathrm{Mg}\left(\mathrm{Si}_{2} \mathrm{O}_{7}\right)$ was proved effective to promote new bone tissue formation in vivo, too [46,47]. FA, found in TT-FaGC, is a natural component of tooth enamel [48]; canasite is biocompatible, although its use for bone repair requires caution due to its tendency to fast resorption in vivo [49]. This limitation could be overcome by properly adjusting the composition of the starting glass through the addition of $\mathrm{SiO}_{2}$ and $\mathrm{AlPO}_{4}$, as suggested by Bubb et al. [50]. The single crystalline phase identified in TT-SCNA, $\mathrm{CaSiO}_{3}$, has been successfully used since the 1980s for osseous repair in load-bearing bone defect sites [51,52].

Other favourable characteristics of the materials prepared in this work include the thermal expansion coefficients that are comparable to those of the tooth structures, which typically range from $8 \times 10^{-6}$ to $11 \times 10^{-6}{ }^{\circ} \mathrm{C}^{-1}$ [53].

It has to be noticed that the density of all the produced glass-ceramic samples, too, closely approaches that of tooth hard substances $\left(\sim 2.5 \mathrm{~g} \cdot \mathrm{cm}^{-3}[5]\right)$.

One of the major challenges in the development of novel dental materials is to produce biomaterials exhibiting mechanical properties able to match those of the tooth hard structures, i.e., dentine and enamel. Table 5 summarizes the major mechanical features of a tooth [5,54-58]. In general, the tooth mechanical properties are dependent on the patient's age $[57,59,60]$; therefore, the choice of one particular material for dental applications rather than another one should ideally be done by taking into account this parameter.

Table 5. Mechanical properties of a natural tooth (data from [5,54-58]).

\begin{tabular}{ccc}
\hline Property & Dentine & Enamel \\
\hline Bending strength $(\mathrm{MPa})$ & $30-120$ & $60-200$ \\
Elastic modulus $(\mathrm{GPa})$ & $18-26$ & $70-100$ \\
Hardness $(\mathrm{GPa})$ & $0.7-0.8$ & $3.0-5.5$ \\
Fracture toughness $\left(\mathrm{MPa} \cdot \mathrm{m}^{1 / 2}\right)$ & $2.4-2.5$ & $1.0-1.5$ \\
\hline
\end{tabular}

Natural enamel and dentine exhibit unique characteristics and, at present, an ideal material able to match all their mechanical properties (strength, stiffness, toughness, hardness) does not exist. From this viewpoint, the glass-ceramics proposed in this work also have some limitations, but they exhibit interesting advantages compared to the majority of dental glass-ceramics commonly proposed in the literature [24].

Materials used for dental implantology should be able to quickly bond to host alveolar bone. TT-CEL2, as demonstrated by in vitro bioactivity tests (Figures 4 and 5), shows a highly bioactive behaviour: in fact, after immersion for just one week in SBF, a compact layer of HA formed on its surface. As reported by many authors, the presence of a HA layer, mimicking the bone mineral, 
promotes cell adhesion and migration, thus allowing the formation of a stable interface between the implant surface and the host bone $[18,20,24]$. It was also demonstrated that osteoblasts preferably attach and spread on HA nano-sized crystals [61]. By comparing the mechanical properties of TT-CEL2 with the data reported in Table 5, it is possible to observe that the bending strength and fracture toughness of TT-CEL2 are comparable to those of dentine. The toughness of traditional glass-ceramics is usually below $1 \mathrm{MPa} \cdot \mathrm{m}^{1 / 2}$, and hence the fracture toughness of most bioceramics proposed in the literature is still far from being appropriate to produce artificial tooth roots. Moreover, it should be considered that the periodontal ligament contributes roughly $1 \mathrm{MPa} \cdot \mathrm{m}^{1 / 2}$ to the fracture toughness in the sound tooth, as it acts to sustain part of the applied load [59]. Thanks to its excellent bioactivity, strength, and toughness, TT-CEL2 may be suggested for a tooth root replacement. However, the elastic modulus and hardness of TT-CEL2 are higher than those of dentine; in particular, the hardness is one order of magnitude higher.

With regard to the materials used for restorative dentistry, they should have proper aesthetics; in addition, bioactivity on the surface of dental restorations must not occur [62]. TT-SCNA qualitatively exhibits an excellent whiteness, which reproduces the appearance of tooth enamel. Moreover, as assessed by soaking in SBF, TT-SCNA has a bioinert-like behaviour. By comparing the data reported in Tables 4 and 5, it is possible to observe that the bending strength and Young's modulus of the TT-SCNA approach those of tooth enamel; in addition, the toughness of TT-SCNA is three times higher than that of natural enamel. Therefore, TT-SCNA shows a great potential as material for restorative dentistry; for example, it could be used to fill enamel cavities or to produce partial/total dental crowns. Future assessment of the translucent characteristics of TT-SCNA will allow drawing more definite conclusions on the aesthetic suitability of this material for dental restoration [63].

As regards TT-FaGC, the situation is more complex. This material exhibits bioactive properties, even if not so good as TT-CEL2, and thus it might be suggested for dental implantology. However, the fracture toughness of TT-FaGC is lower than that of natural dentine. Potential suitability of TT-FaGC for enamel restoration may be suggested, too, considering that its bending strength is comparable to that of enamel and its Young's modulus is not much lower than that of enamel. In addition, the toughness of TT-FaGC is twice as high as that of enamel. Finally, the presence of FA crystals could impart an anti-cariotic effect to the material inducing enamel remineralisation, as reported by some authors [64]. Fluoride release from the residual glassy phase of TT-FaGC deserves to be studied: this could represent a significant added value of the material as the ability to release fluoride into the surroundings of the restored zone can induce the precipitation of natural FA, thus enhancing the enamel remineralization. TT-FaGC qualitatively shows an excellent whiteness, too, thus potentially matching the aesthetic appearance of tooth enamel; however, the translucent characteristics of this material remain to be properly studied.

The prototype of a full-ceramic implant for total tooth substitution, coupling a TT-CEL2 layer with a TT-SCNA layer, was successfully tailored. The two layers were effectively joined together without any defect or flaw at the interface (Figure 7). The TT-CEL2 layer should act to replace the tooth root, allowing the implant to bond to alveolar bone due to the high bioactivity of the glass-ceramic (Figures 8 and 9). The TT-SCNA layer should act as a dental crown, replacing the tooth enamel. The potential of such a bilayered implant could be highly significant. An interesting application, which will be investigated in future works, could be the following: by means of tomographical analyses carried out on the patient's set of teeth, it would be possible to reconstruct a model of the tooth that must be substituted; hence, a negative mould of the tooth structure and morphology can be fabricated. TT-CEL2 and TT-SCNA powders can be compacted into the mould and finally sintered to produce an implant able to perfectly mimic the shape and size of the patient's original tooth. Alternatively, additive manufacturing could be used to fabricate a tooth-like implant; furthermore, this latter approach could be very valuable to reduce the porosity of the final implant and, thus, increase its mechanical properties. 
Future research work should be carried out to extend and support these promising achievements, such as biological in vitro experiments with appropriate cell types and durability tests using solutions that mimic the physiological conditions (e.g., $\mathrm{pH}$ ) in the oral cavity.

\section{Conclusions}

Thermal, microstructural, mechanical, and bioactive investigations were carried out on three experimental glass-ceramics (TT-CEL2, TT-FaGC, and TT-SCNA), produced by the thermal treatment of parent silicate glasses, to determine their potential suitability for dental applications. TT-CEL2 shows mechanical properties comparable to those of natural dentine and an excellent apatite-forming ability in SBF (in vitro bioactivity); for these reasons, its use may be promising to replace the roots of the teeth. TT-SCNA is bioinert upon immersion in SBF and exhibits mechanical properties close to those of tooth enamel: therefore, it may be suggested for potential use in restorative dentistry for filling enamel cavities or as material for dental crown fabrication. TT-FaGC may be suggested as material for enamel restoration, too, and is expected to exhibit in vivo anti-carotic properties. Finally, a bilayered TT-CEL2/TT-SCNA prototype implant was successfully fabricated and proposed for total tooth replacement. This approach represents a novel, attractive option to replace and regenerate dental structures, which deserves further investigation and future in-depth analysis.

Author Contributions: F.B. designed the study, performed all the experiments, interpreted the data and wrote the paper. E.V. interpreted the data and wrote the paper.

Conflicts of Interest: The authors declare no conflict of interest.

\section{References}

1. Bayne, S.C. Dental biomaterials: Where are we and where are we going? J. Dent. Educ. 2005, 69, 571-585. [PubMed]

2. Cho, Y.D.; Seol, Y.J.; Lee, Y.M.; Rhyu, I.C.; Ryoo, H.M.; Ku, Y. An overview of biomaterials in periodontology and implant dentistry. Adv. Mater. Sci. Eng. 2017, 2017, 1948241. [CrossRef]

3. Bhargavi, A.; Ajay, S.; Rohit, B.; Vishal, A.; Minkle, G. Comparative tooth anatomy-A review. Int. J. Dent. Sci. Res. 2013, 1, 34-37. [CrossRef]

4. Denry, I.L.; Holloway, J.A.; Rosenstiel, S.F. Crystallization kinetics of a low-expansion feldspar glass for dental applications. J. Biomed. Mater. Res. 1998, 41, 398-404. [CrossRef]

5. Ramalho, A.; Antunes, P.V. Reciprocating wear test of dental composites against human teeth and glass. Wear 2007, 263, 1095-1104. [CrossRef]

6. Weiss, P.; Lapkowski, M.; LeGeros, R.Z.; Bouler, J.M.; Jean, A.; Daculsi, G. Fourier-transform infrared spectroscopy study of an organic-mineral composite for bone and dental substitute materials. J. Mater. Sci. Mater. Med. 1997, 8, 621-629. [CrossRef] [PubMed]

7. Sakaguchi, R.L. Review of the current status and challenges for dental posterior restorative composites: Clinical, chemistry, and physical behavior considerations (Summary of discussion from the Portland Composites Symposium (POCOS) 17-19 June 2004, Oregon Health \& Science University, Portland, Oregon). Dent. Mater. 2005, 21, 3-6. [PubMed]

8. Sajewicz, E. On evaluation of wear resistance of tooth enamel and dental materials. Wear 2005, 260, 1256-1261. [CrossRef]

9. Holand, W.; Frank, M.; Rheinberger, V. Surface crystallization of leucite in glasses. J. Non-Cryst. Solids 1995, 180, 292-307. [CrossRef]

10. Cattell, M.J.; Chandwick, T.C.; Knowles, J.C.; Clarke, R.L.; Samarawickrama, D.Y.D. The nucleation and crystallization of fine grained leucite glass-ceramics for dental applications. Dent. Mater. 2006, 22, 925-933. [CrossRef] [PubMed]

11. Holand, W.; Rheinberger, V.; Apel, E.; Van't Hoen, C. Principles and phenomena of bioengineering with glass-ceramics for dental restoration. J. Eur. Ceram. Soc. 2007, 27, 1521-1526. [CrossRef]

12. Ananth, H.; Kundapur, V.; Mohammed, H.S.; Anand, M.; Amarnath, G.S.; Mankar, S. A review on biomaterials in dental implantology. Int. J. Biomed. Sci. 2015, 11, 113-120. [PubMed] 
13. Hong, M.H.; Min, B.K.; Kwon, T.Y. Fabricating high-quality 3D-printed alloys for dental applications. Appl. Sci. 2017, 7, 710. [CrossRef]

14. Rohanizadeh, R.; LeGeros, R.Z.; Harsono, M.; Bendavid, A. Adherent apatite coating on titanium substrate using chemical deposition. J. Biomed. Mater. Res. A 2005, 72, 428-438. [CrossRef] [PubMed]

15. Ozawa, N.; Negami, S.; Odaka, T.; Morii, T.; Koshino, T. Histological observations on tissue reaction of the rat calcaneal tendon to sintered hydroxyapatite. J. Mater. Sci. Lett. 1989, 8, 869-871. [CrossRef]

16. Albrektsson, T.; Branemark, P.I.; Hansson, H.A.; Kasemo, B.; Larsson, K.; Lundstrom, I.; McQueen, D.H.; Skalak, R. The interface zone of inorganic implants in vivo: Titanium implants in bone. Ann. Biomed. Eng. 1983, 11, 1-27. [CrossRef]

17. Cochran, D.L.; Schenk, R.K.; Lussi, A.; Higginbottom, F.L.; Buser, D. Bone response to unloaded and loaded titanium implants with a sandblasted and acid-etched surface: A histometric study in the canine mandible. J. Biomed. Mater. Res. 1998, 40, 1-11. [CrossRef]

18. Palka, V.; Ivan, J.; Postrkova, E.; Kolenciak, V.; Krsek, A.; Infner, I.; Koerten, H.K. The effect of biological environment on the surface of titanium and plasma-sprayed layer of hydroxylapatite. J. Mater. Sci. Mater. Med. 1998, 9, 369-373. [CrossRef] [PubMed]

19. Jayaswal, G.P.; Dange, S.P.; Khalikar, A.N. Bioceramic in dental implants: A review. J. Indian Prosthodont. Soc. 2010, 10, 8-12. [CrossRef] [PubMed]

20. Abbasi, Z.; Bahrololoom, M.E.; Shariat, M.H.; Bagheri, R. Bioactive glasses in dentistry: A review. J. Dent. Biomater. 2015, 2, 1-9.

21. Jitaru, S.; Hodisan, I.; Timis, L.; Lucian, A.M.; Bud, M. The use of bioceramics in endodontics-Literature review. Clujul Med. 2016, 89, 470-473.

22. Al-Haddad, A.; Che Ab Aziz, Z.A. Bioceramic-based root canal sealers: A review. Int. J. Biomater. 2016, 2016, 9753210. [CrossRef] [PubMed]

23. Wren, A.W. Vitreous materials for dental restoration and reconstruction. Adv. Struct. Mater. 2016, 53, $203-225$.

24. Montazerian, M.; Zanotto, E.D. Bioactvie and inert dental glass-ceramics. J. Biomed. Mater. Res. A 2017, 105, 619-639. [CrossRef] [PubMed]

25. Verné, E.; Vitale-Brovarone, C.; Bui, E.; Bianchi, C.L.; Boccaccini, A.R. Surface functionalization of bioactive glasses. J. Biomed. Mater. Res. A 2009, 90, 981-992. [CrossRef] [PubMed]

26. Vitale-Brovarone, C.; Baino, F.; Miola, M.; Mortera, R.; Onida, B.; Verné, E. Glass-ceramic scaffolds containing silica mesophases for bone grafting and drug delivery. J. Mater. Sci. Mater. Med. 2009, 20, 809-820. [CrossRef] [PubMed]

27. Baino, F.; Ferraris, M.; Bretcanu, O.; Verné, E.; Vitale-Brovarone, C. Optimization of composition, structure and mechanical strength of bioactive 3-D glass-ceramic scaffolds for bone substitution. J. Biomater. Appl. 2013, 27, 872-890. [CrossRef] [PubMed]

28. Ma, H.; Baino, F.; Fiorilli, S.; Vitale-Brovarone, C.; Onida, B. Al-MCM-41 inside a glass-ceramic scaffold: A meso-macroporous system for acid catalysis. J. Eur. Ceram. Soc. 2013, 33, 1535-1543. [CrossRef]

29. ISO 6872:2015. Dentistry-Ceramic Materials. Available online: https://www.iso.org/standard/59936.html (accessed on 18 November 2017).

30. Anstis, G.R.; Chantikul, P.; Lawn, B.R.; Marshall, D.B. A critical evaluation of indentation techniques for measuring fracture toughness: I, direct crack measurements. J. Am. Ceram. Soc. 1981, 64, 533-538. [CrossRef]

31. ASTM C1259-14. Standard Test Method for Dynamic Young's Modulus, Shear Modulus, and Poisson's Ratio for Advanced Ceramics by Impulse Excitation of Vibration. 2014. Available online: https:/ / compass.astm. org/Standards/HISTORICAL/C1259-14.htm (accessed on 18 November 2017).

32. Labella, R.; Lambrechts, P.; Van Meerbeek, B.; Vanherle, G. Polymerization shrinkage and elasticity of flowable composites and filled adhesives. Dent. Mater. 1999, 15, 128-137. [CrossRef]

33. Kokubo, T.; Takadama, H. How useful is SBF in predicting in vivo bone bioactivity? Biomaterials 2006, 27, 2907-2915. [CrossRef] [PubMed]

34. Clifford, A.; Hill, R.G.; Towler, M.R.; Wood, D.J. The crystallisation of glasses from the ternary $\mathrm{CaF}_{2}-\mathrm{CaAl}_{2} \mathrm{Si}_{2} \mathrm{O}_{8}-\mathrm{P}_{2} \mathrm{O}_{5}$ system. J. Mater. Sci. 2001, 36, 3955-3961. [CrossRef]

35. Kaur, G.; Pandey, O.P.; Singh, K.; Homa, D.; Scott, B.; Pickrell, G. A review of bioactive glasses: Their structure, properties, fabrication and apatite formation. J. Biomed. Mater. Res. A 2014, 102, $254-274$. [CrossRef] [PubMed] 
36. Hench, L.L.; Splinter, R.J.; Allen, W.C.; Greenlee, T.K. Bonding mechanisms at the interface of ceramic prosthetic materials. J. Biomed. Mater. Res. 1971, 5, 117-141. [CrossRef]

37. Wilson, J.; Pigott, G.H.; Schoen, F.J.; Hench, L.L. Toxicology and biocompatibility of bioglasses. J. Biomed. Mater. Res. 1981, 15, 805-817. [CrossRef] [PubMed]

38. Hench, L.L. Bioactive ceramics. Ann. N. Y. Acad. Sci. 1988, 523, 54-71. [CrossRef] [PubMed]

39. Baino, F. Porous glass-ceramic orbital implants: A feasibility study. Mater. Lett. 2018, 212, 12-15. [CrossRef]

40. Baino, F.; Verné, E.; Vitale-Brovarone, C. 3-D high strength glass-ceramic scaffolds containing fluoroapatite for load-bearing bone portions replacement. Mater. Sci. Eng. C 2009, 29, 2055-2062. [CrossRef]

41. Vitale-Brovarone, C.; Baino, F.; Verné, E. High strength bioactive glass-ceramic scaffolds for bone regeneration. J. Mater. Sci. Mater. Med. 2009, 20, 643-653. [CrossRef] [PubMed]

42. Lefebvre, L.; Chevalier, J.; Gremillard, L.; Zenati, R.; Thollet, G.; Bernache-Assolant, D.; Govin, A. Structural transformations of bioactive glass $45 \mathrm{~S} 5$ with thermal treatments. Acta Mater. 2007, 55, 3305-3313. [CrossRef]

43. Boccaccini, A.R.; Chen, Q.Z.; Lefebvre, L.; Gremillard, L.; Chevalier, J. Sintering, crystallisation and biodegradation behaviour of Bioglass ${ }^{\circledR}$-derived glass-ceramics. Faraday Discuss. 2007, 136, 27-44. [CrossRef] [PubMed]

44. Bretcanu, O.; Chatzistavrou, X.; Paraskevpoulos, K.; Conradt, R.; Thompson, I.; Boccaccini, A.R. Sintering and crystallization of $45 S 5$ Bioglass ${ }^{\circledR}$ powder. J. Eur. Ceram. Soc. 2009, 29, 3299-3306. [CrossRef]

45. Jones, J.R.; Brauer, D.S.; Hupa, L.; Greenspan, D.C. Bioglass and bioactive glasses and their impact on healthcare. Int. J. Appl. Glass Sci. 2016, 7, 423-434. [CrossRef]

46. Wu, C.; Chang, J.; Zhai, W.; Ni, S.; Wang, J. Porous akermanite scaffolds for bone tissue engineering: Preparation, characterization, and in vitro studies. J. Biomed. Mater. Res. B (Appl. Biomater.) 2006, 78, 47-55. [CrossRef] [PubMed]

47. Huang, Y.; Jin, X.; Zhang, X.; Sun, H.; Tu, J.; Tang, T.; Chang, J.; Dai, K. In vitro and in vivo evaluation of akermanite bioceramics for bone regeneration. Biomaterials 2009, 30, 5041-5048. [CrossRef] [PubMed]

48. Boskey, A.L. Mineralization of bones and teeth. Elements 2007, 6, 385-392. [CrossRef]

49. Da Rocha Barros, V.M.; Salata, L.A.; Sverzut, C.E.; Xavier, S.P.; Van Noort, R.; Johnson, A.; Hatton, P.V. In vivo bone tissue response to a canasite glass-ceramic. Biomaterials 2002, 23, 2895-2900. [CrossRef]

50. Bubb, N.L.; Wood, D.; Streit, J.P. Reduction of the solubility of fluorcanasite based glass ceramics by additions of $\mathrm{SiO}_{2}$ and $\mathrm{AlPO}_{4}$. Glass Technol. 2004, 45, 91-93.

51. Kokubo, T.; Ito, S.; Sakka, S.; Yamamuro, T. Formation of a high-strength bioactive glass-ceramic in the system $\mathrm{MgO}-\mathrm{CaO}-\mathrm{SiO}_{2}-\mathrm{P}_{2} \mathrm{O}_{5}$. J. Mater. Sci. 1986, 21, 536-540. [CrossRef]

52. Sautier, J.M.; Kokubo, T.; Ohtsuki, T.; Nefussi, J.R.; Boulekbache, H.; Oboeuf, M.; Loty, S.; Loty, C.; Forest, N. Bioactive glass-ceramic containing crystalline apatite and wollastonite initiates biomineralization in bone cell cultures. Calcif. Tissue Int. 1994, 55, 458-466. [CrossRef] [PubMed]

53. Kraft, L.; Engqvist, H.; Hermansson, L. Early-age deformation, drying shrinkage and thermal dilation in a new type of dental restorative material based on calcium aluminate cement. Cem. Concr. Res. 2004, 34, 439-446. [CrossRef]

54. Fong, H.; Sarikaya, M.; White, S.N.; Snead, M.L. Nano-mechanical properties profiles across dentin-enamel junction of human incisor teeth. Mater. Sci. Eng. C 2000, 7, 119-128. [CrossRef]

55. Finke, M.; Hughes, J.A.; Parker, D.M.; Jandt, K.D. Mechanical properties of in situ demineralised human enamel measured by AFM nanoindentation. Surf. Sci. 2001, 491, 456-467. [CrossRef]

56. Mahoney, E.K.; Rohanizadeh, R.; Ismail, F.S.M.; Kilpatrick, N.M.; Swain, M.V. Mechanical properties and microstructure of hypomineralised enamel of permanent teeth. Biomaterials 2004, 25, 5091-5100. [CrossRef] [PubMed]

57. Park, S.; Wang, D.H.; Zhang, D.; Romberg, E.; Arola, D. Mechanical properties of human enamel as a function of age and location in the tooth. J. Mater. Sci. Mater. Med. 2008, 19, 2317-2324. [CrossRef] [PubMed]

58. Yan, J.; Taskonak, B.; Platt, J.A.; Mecholsky, J.J., Jr. Evaluation of fracture toughness of human dentin using elastic-plastic fracture mechanics. J. Biomech. 2008, 41, 1253-1259. [CrossRef] [PubMed]

59. Kinney, J.H.; Nalla, R.K.; Pople, J.A.; Breunig, T.M.; Ritchie, R.O. Age-related transparent root dentin: Mineral concentration, crystallite size, and mechanical properties. Biomaterials 2005, 26, 3363-3376. [CrossRef] [PubMed]

60. Low, I.M.; Duraman, N.; Mahmood, U. Mapping the structure, composition and mechanical properties of human teeth. Mater. Sci. Eng. C 2008, 28, 243-247. [CrossRef] 
61. Schwartz, Z.; Boyan, B.D. Underlying mechanisms at the bone-biomaterial interface. J. Cell. Biochem. 1994, 56, 340-347. [CrossRef] [PubMed]

62. ElBatal, F.H.; Azooz, M.A.; Hamdy, Y.M. Preparation and characterization of some multicomponent silicate glasses and their glass-ceramics derivatives for dental applications. Ceram. Int. 2009, 35, 1211-1218. [CrossRef]

63. Lee, Y.K. Translucency of dental ceramic, post and bracket. Materials 2015, 8, 7241-7249. [CrossRef] [PubMed]

64. Wiegand, A.; Buchalla, W.; Attin, T. Review on fluoride-releasing restorative materials-fluoride release and uptake characteristics, antibacterial activity and influence on caries formation. Dent. Mater. 2007, 23, 343-362. [CrossRef] [PubMed]

(C) 2017 by the authors. Licensee MDPI, Basel, Switzerland. This article is an open access article distributed under the terms and conditions of the Creative Commons Attribution (CC BY) license (http:/ / creativecommons.org/licenses/by/4.0/). 